\title{
Gradhiva
}

GRADHIV

Revue d'anthropologie et d'histoire des arts

$11 \mid 2010$

Grands hommes vus d'en bas

\section{L'affiche Hope}

Portrait d'Obama comme Géant et comme virus

The Hope poster. Obama as giant and as virus

\section{Béatrice Fraenkel}

\section{CpenEdition}

\section{Journals}

Édition électronique

URL : http://journals.openedition.org/gradhiva/1685

DOI : 10.4000/gradhiva.1685

ISSN : 1760-849X

Éditeur

Musée du quai Branly Jacques Chirac

Édition imprimée

Date de publication : 19 mai 2010

Pagination : 118-139

ISBN : 978-2-35744-025-8

ISSN : 0764-8928

Référence électronique

Béatrice Fraenkel, «L'affiche Hope », Gradhiva [En ligne], 11 | 2010, mis en ligne le 19 mai 2013 consulté le 19 avril 2019. URL : http://journals.openedition.org/gradhiva/1685 ; DOI : 10.4000/ gradhiva. 1685

(c) musée du quai Branly 


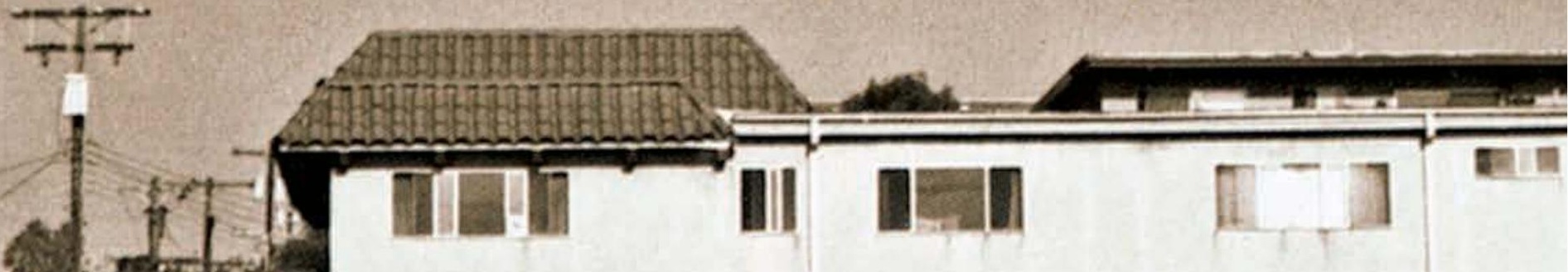

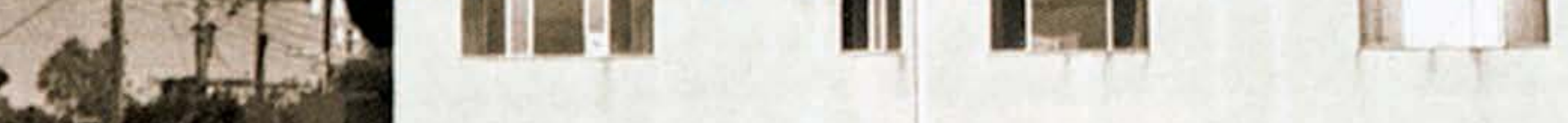
n.
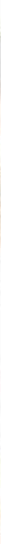


\section{L'affiche Hope Portrait d'Obama comme Géant et comme virus}

Béatrice Fraenkel

Fig. 1 L'affiche Obey dans les rues de Santa Monica. Droits réservés.
La carrière exceptionnelle de l'affiche Hope est incontestable. En tant que portrait de Barack Obama, elle est devenue le support médiatique le plus remarqué d'une campagne politique reconnue par tous les spécialistes comme l'une des plus réussies de l'histoire américaine. Pour certains, elle s'inscrit dans la plus haute lignée des illustrations politiques et serait tout aussi remarquable que l'image fameuse Uncle Sam wants you à l'index pointé. Elle a déjà sa rubrique sur Wikipédia et a même créé un genre en soi : le logiciel Obamicon transforme toute image en portrait «à la manière » de Hope. On peut «obamaïser » n'importe qui.

Pendant la campagne électorale, une contre-affiche tendancieuse dite Joker (fig. 2) a levé contre elle une majorité d'Américains. La mauvaise affiche, honnie et dénoncée, fait face à la bonne affiche Hope, encensée et panthéonisée. Car non seulement Hope a fait la couverture du Times et d'Esquire, mais elle a aussi été installée à la très select National Portrait Gallery de Washington (fig. 3), qui a fait l'acquisition de la version originale. Or l'œuvre désormais célèbre du graphiste Shepard Fairey s'est faite à contresens du parcours attendu : il s'agit bien d'une image du candidat Barack Obama, futur président des États-Unis, mais elle n'a pas été élaborée par les responsables de la campagne présidentielle puis réutilisée par d'autres. Bien au contraire, cette affiche a été créée en dehors des quartiers généraux officiels. Nous commençons donc notre enquête par le constat d'un paradoxe : c'est Fairey, graphiste indépendant, supporter du candidat, qui a pris les devants. Constatant qu'il n'existait pas de portrait officiel du candidat, il en crée un qu'il décline en plusieurs affiches (Progress et Hope) diffusées sur son site Internet. Le succès est immédiat; c'est alors que le staff d'Obama lui demande de faire une affiche pour la campagne officielle. C'est donc du dehors que s'est imposée l'image, comme si l'on rappelait à des professionnels de la politique qu'ils oubliaient, dans leur hâte à innover, une pièce maîtresse de toute propagande : le portrait officiel. 


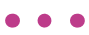

1. Voir l'article de Noam Cohen (New York Times 2009).

2. C'est d'ailleurs en tant que contribuable que Fairey revendique le droit de s'exprimer dans l'espace public : «As taxpayers we all own the public space, but the government and advertisers frequently control it. I prefer to see the public space used as a forum of expression. This, of course, has to be done in a logical and respectful way; good street art, properly integrated, only enhances a city with visual simulations and or flow of ideas. Advertisers, however, don't want any competition. Don't let the advertisers' agendas dictate how your streets are used. 》 [2009: 304)
Second constat, tout aussi surprenant : l'auteur de l'affiche Hope, loin d'être un professionnel du marketing, appartient au monde des street artists. Il pratique plutôt le pochoir que le graffiti, mais s'est illustré depuis de nombreuses années dans des actions d'affichage sauvage (posters, flyers) qui lui ont valu quatorze arrestations (Fairey 2009 : 295), plusieurs condamnations et quelques séjours en prison. La rencontre entre le colleur de stickers et l'énorme machine de communication électorale du candidat démocrate est parfaitement inédite - ironique penseront certains. Elle correspond tout à fait à l'esprit de la campagne. Certes, Fairey jouissait d'une certaine renommée comme D.J., auteur de t-shirts, de pochettes de disques, et surtout de posters, stickers et vinyles; il était déjà un ancien de la scène punk rock où il officiait depuis vingt ans. Avec l'affiche Hope, il accède à une nouvelle catégorie, celle des artistes à réputation mondiale. L'Institute of Contemporary Art (ICA) de Boston ne s'y est pas trompé, qui lui a consacré une rétrospective importante en février 2009.

Salué comme un coup du staff de campagne et un clin d'œil en direction d'un public jeune, le cas s'est compliqué de deux incidents : l'Associated Press a déposé une plainte contre Fairey après avoir découvert que la photographie qu'il avait utilisée pour réaliser l'affiche avait été "volée " à un journaliste freelance de l'agence, Mannie Garcia. Le Washington Post, dans lequel cette photo avait paru, a également porté plainte. La fabrication de l'affiche Hope est donc au centre d'un procès, accompagné d'un vaste débat sur le statut des photographies de presse ${ }^{1}$. Fairey, qui avait pris la tête d'une croisade pour l'accès libre et gratuit aux photographies de presse, a reconnu avoir menti au tribunal et falsifié le dossier de conception de l'affiche, cachant les preuves du vol de l'image publiée. Il a, depuis, présenté des excuses publiques. En février 2009, une très forte émotion avait saisi les fans du graphiste venus en masse assister à une fête organisée à l'occasion de l'exposition de l'ICA. Fairey, qui devait y officier comme D.J., fut arrêté par la police de Boston pour d'anciens délits d'affichage sauvage. Un bon avocat réussit à démontrer que les faits reprochés avaient été commis dans le Massachusetts et Fairey fut relâché quelques heures plus tard. Ces rebondissements judiciaires et policiers ne font qu'amplifier l'aura d'illégalité qui entoure l'artiste, qui se présente par ailleurs comme bon père de famille et honnête contribuable².

Tous ces faits sont bien connus, ils constituent la légende médiatique qui entoure l'affiche Hope et son créateur. Ajoutons un dernier ingrédient au récit, l'élément qui incite à une analyse plus approfondie : l'immense succès de l'affiche. Succès commercial (Fairey raconte comment, lors de la mise en vente du poster sur Internet, le succès fut immédiat et la vente un véritable jackpot qui rapporta 375000 dollars en quelques minutes), succès militant et succès professionnel : l'affiche Hope est un événement dans l'événement de l'élection d'Obama.

Pour mener à bien notre analyse, nous avons choisi de mêler plusieurs approches susceptibles de faire apparaître l'affiche Hope dans toute son épaisseur opératoire. Il fallait dépasser l'agitation qu'elle provoque, mener diverses enquêtes et s'interroger sur plusieurs énigmes qu'elle semble receler. Ainsi, elle ne semble pas valoir pour ce qu'elle montre, pour ses qualités plastiques intrinsèques. Elle est volontiers qualifiée d'image "vide" et vaudrait surtout par ce qu'elle suggère de son origine. Elle plairait parce qu'elle évoque une manière de faire plus que par le résultat de ce faire. Nous verrons comment elle rend visible son propre processus de fabrication et s'affirme ainsi comme une sorte de relique d'un monde perdu. 
Ensuite, nous examinerons l'agence de production de cette affiche, la marque Obey Giant. Fondée par Fairey en 1989, elle a été conçue comme un service de propagande mis à la disposition d'un être fictif, André le Géant. Depuis, cette curieuse agence s'est développée, est devenue une véritable entreprise qui fabrique des produits publicitaires et revendique son expertise en propagande. Par la voix de son fondateur, elle se réclame d'une théorie cohérente de la communication publique et s'est particulièrement distinguée dans ses pratiques de diffusion. Il nous semble que l'affiche Hope doit être comprise comme un produit né du savoir-faire de cet étrange atelier qu'est Obey Giant. En particulier, il peut être pertinent de questionner la réalité d'un lien entre André le Géant et Obama, et plus largement de mieux comprendre dans quelle famille de héros Obama est entré puisque l'agence s'est mise au service d'une cohorte de «leaders » qu'elle exalte.

Enfin, après avoir examiné l'affiche comme œuvre graphique et l'avoir située dans son contexte de production, nous la saisirons dans l'histoire de sa carrière fulgurante, les quelques mois de la campagne présidentielle d'Obama. C'est en effet en tant qu'objet de campagne mis au service du candidat et venant enrichir le kit des militants que l'af-

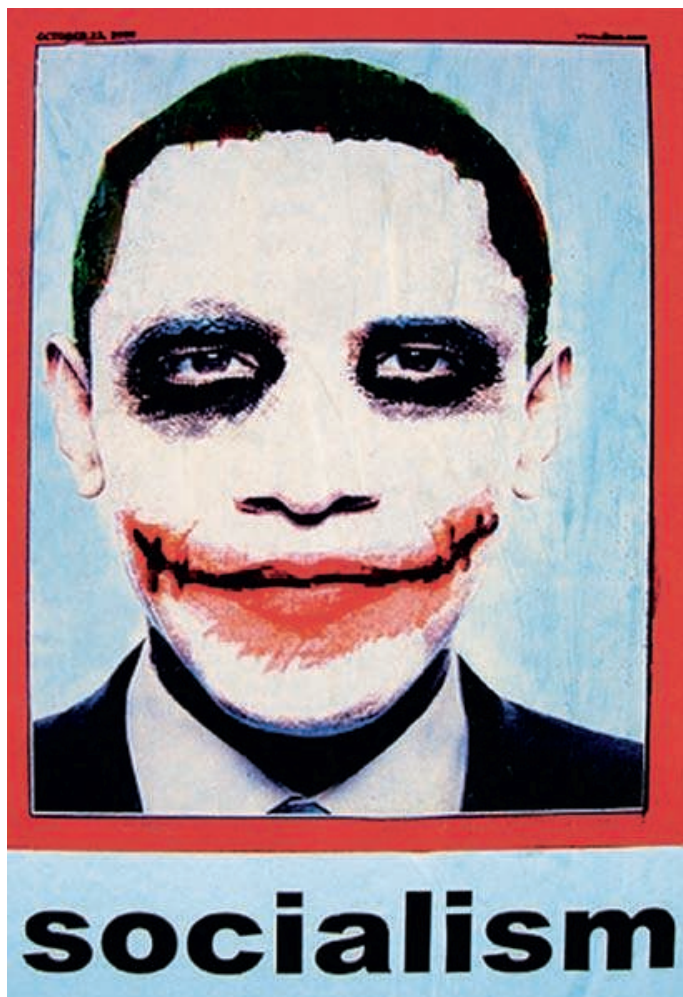

fiche a déployé toute sa force de frappe. Nous verrons comment les options choisies pour organiser le marketing politique du sénateur de l'Illinois ont recoupé, curieusement, l'idéologie de l'agence Obey Giant pour produire ce qu'il convient désormais d'appeler, dans le jargon des professionnels, une «image virale».

Au terme de l'enquête sur l'affiche Hope, un renversement de point de vue s'imposera : en examinant les strates qui semblaient la composer, nous arriverons à un constat imprévu. L'affiche est à l'interface de plusieurs réseaux, essentiellement les réseaux du street art et du marketing politique qui, loin d'être contradictoires, sont liés par une série d'atomes crochus et peuvent être vus comme deux laboratoires qu'anime un même projet de recherche sur la propagation. Deux laboratoires qui doivent être confrontés aux idéaux d'un certain Obama, dont le passé de community organizer ${ }^{3}$ semble être ancré dans une tout autre conception de l'espace public que celui produit par l'affiche Hope.

\section{L'affiche Hope : une image vide?}

Les témoignages qui entourent la création de l'affiche, en particulier les discours tenus par Fairey lui-même, contribuent à en faire un objet particulier doté de valeurs et de pouvoirs exceptionnels. Retenons deux anecdotes souvent confiées par le graphiste aux journalistes. La première nous apprend qu'avant même d'être créée, l'affiche se distinguait déjà par les circonstances exceptionnelles de sa commande. Lors d'un entretien réalisé par le journaliste William Booth (Washington Post 2008), Fairey raconte qu'il avait confié à son ami Yosi Sergant, publicitaire bien introduit auprès de démocrates proches d'Obama, qu'il souhaitait agir pour le candidat. Quelque temps plus tard, «on » lui fait savoir qu'il peut se lancer. "Who said, exactly? » demande le journaliste. Réponse de
Fig. 2 Affiche caricaturant Obama en joker, campagne présidentielle 2008. Droits réservés.

\section{-}

3. Nous préférons garder le terme anglais car sa traduction pose problème : la notion d'«animateur social » serait la plus appropriée, mais elle ne rend pas compte de l'ancrage historique du mouvement américain d'organisation des communautés. Nous évoquerons plus loin l'importance de cette référence pendant la campagne électorale. 
-

4. La charte graphique d'un candidat est un vrai sujet aux États-Unis. Cf. un article fouillé d'Adam Tshorn dans le Los Angeles Times (2008) comparant l'Optima classique choisie par McCain (police créée en 1958) et le New Baskerville d'Hillary Clinton (créée en 1757) au Gotham d'Obama. Le choix a été amplement commenté sur la blogosphère, et débattu à la radio et à la télévision.
Fairey : "You can assume this came from the highest levels. » Le caractère allusif du propos pose sur l'affiche un premier vernis de légende. Chaque lecteur comprend qu'elle fut patronnée au plus haut niveau, par le futur président luimême. Seconde anecdote qui vient conforter les origines merveilleuses du poster : l'artiste nous apprend qu'il fut réalisé vite, quasiment sans travail, comme sous une impulsion particulière. Mais surtout, il révèle qu'une heureuse coïncidence a préfiguré la destinée de l'œuvre : la première esquisse est réalisée le 31 janvier 2008, jour de la naissance de sa fille Madeline. Ainsi, plusieurs fées se sont penchées sur le berceau de l'icône, représentant des dons différents : la volonté du "Grand ", le souffle de la Muse, le pouvoir de donner la vie.

Loin de ces anecdotes touchantes, c'est du document que nous souhaitons partir, de l'affiche elle-même, en examinant ce qu'elle montre et comment elle montre Obama. Elle combine quatre éléments de provenances différentes : une typographie, un logo, un message et l'image enfin, qui est elle-même issue d'une photographie prise en 2006 par un photographe indépendant, retravaillée par le graphiste. Comme nombre d'affiches (Sontag 1999 [1970] : 199), Hope relève d'emprunts (la photographie) et de contraintes imposées (la typographie, le logo), le tout efficacement assemblé par un professionnel du design graphique; c'est une composition «appliquée » à une situation.

\section{UNE POLICE : LE GOTHAM}

Dès le début de la campagne électorale, les journalistes et les professionnels avaient salué le choix d'une police de caractère, le Gotham, qu'Obama avait choisi d'adopter pour tous les supports de sa propagande ${ }^{4}$. Cette police a été dessinée par Frere-Jones pour le magazine $G Q$, qui cherchait un «type masculin, frais et versatile ». Les lettres géométriques du Gotham sont sans sérif et s'inspirent des polices utilisées dans le bâtiment à New York dans les années 1960. Elles ont été tracées à partir du lettrage du terminal de bus de la $8^{\mathrm{e}}$ Avenue. Le Gotham est donc une émanation des écritures urbaines, une police typiquement américaine, populaire, qui renvoie tout autant aux frontons qu'aux enseignes et rappelle les stations-services photographiées par Ed Ruscha. Pour nombre de typographes, elle possède la rare qualité d'être «lisible mais pas jaillissante " : le module carré du mot hope apparaît solide et simple sans être dominateur.

Autre élément, le logo porté en badge sur le revers de la veste d'Obama, qui représente un astre au-dessus d'un horizon. Beaucoup y ont vu un soleil levant, et surtout une image cryptée véhiculant un message caché, le « $\mathrm{O}$ » astral d'Obama. Le message, "Hope», a aussi son histoire. Ce sont les militants qui l'ont plébiscité alors que Fairey préférait « Progress ». «Hope » présente la particularité d'être un message ambigu. En anglais, le terme peut désigner un ordre : «Espérez! » ou bien un nom, "espoir». Dans un cas c'est Obama qui nous parle ("Espérez!»), dans l'autre c'est un jugement qui est porté sur lui («Il est l'espoir » ou «Voici l'espoir »). C'est précisément cette ambiguïté qui a séduit les militants, tout comme, sans doute, le contenu vaguement religieux de cette notion.

\section{UNE IMAGE VIDE?}

Pour le citoyen de base, l'affiche tranche avec la loi du genre. L'image surprend par son pouvoir d'évocation d'un univers graphique du passé. Il y a de la citation dans cette œuvre, plus précisément un ensemble de références amalgamées, un 


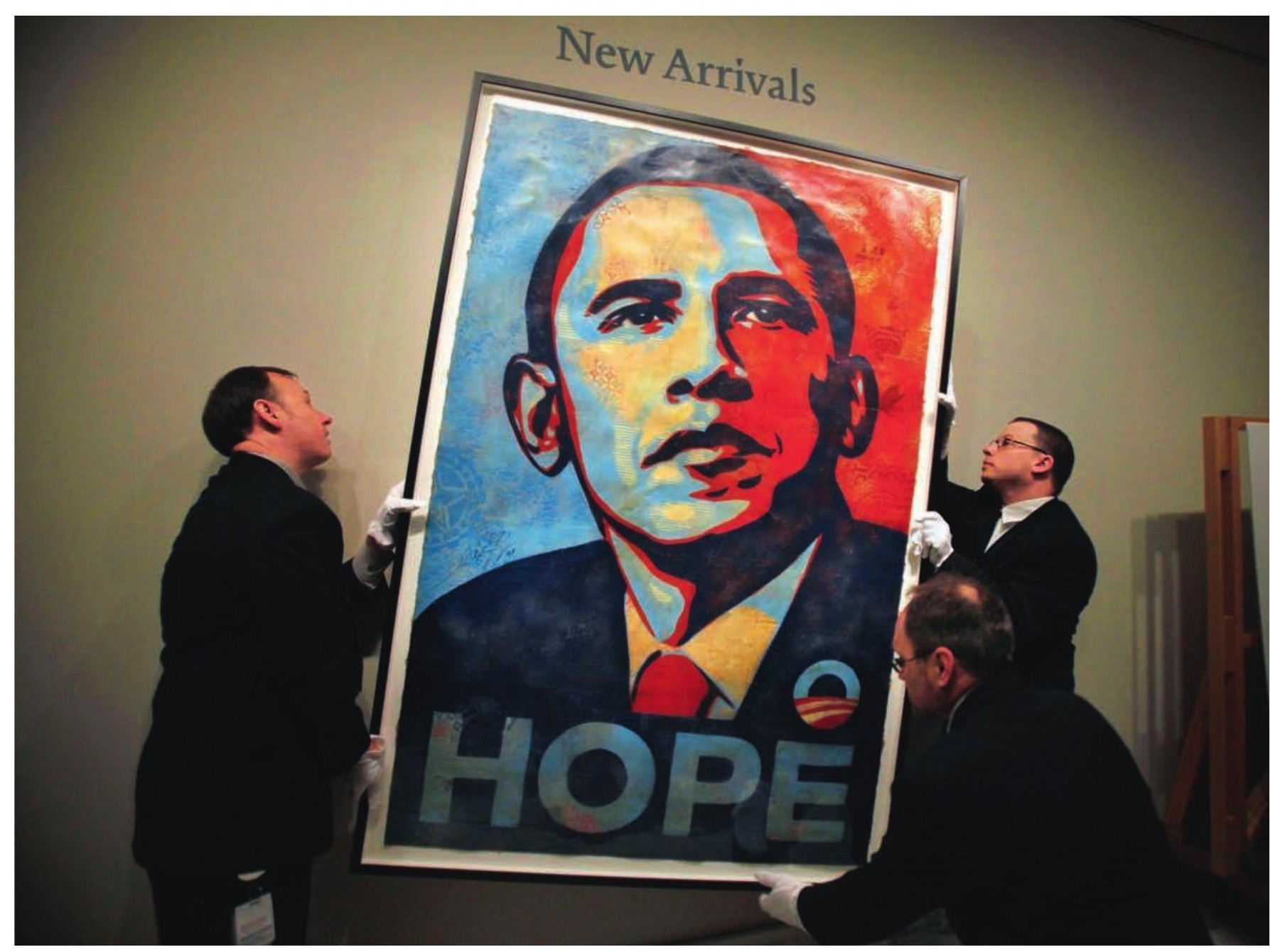

Fig. 3 Accrochage de l'affiche Hope à la National Portrait Gallery de Washington, États-Unis @ AP/Sipa.

feuilleté d'images. S'agit-il d'un portrait façon Che Guevara, est-il inspiré d'une affiche de match de boxe ou traité à la manière d'une pochette de disque? Tout cela et plus encore. Nombre de commentateurs ont reconnu l'influence d'Andy Warhol, de Barbara Kruger, du réalisme soviétique, de la propagande maoïste, ou encore de Diego Rivera ou de Flash Gordon. Fairey lui-même a revendiqué l'emprunt à des maîtres divers, surtout Warhol, et assume pleinement un droit d'usage et de citation des œuvres dont il a besoin. "Quand je choisis les images, tous les clichés iconographiques des leaders, des gens de la culture populaire, tout ce qui a eu un profond effet sur moi, du portrait de Jimi Hendrix par John Van Hamersveld au portrait de Guevara aux graphismes très contrastés... toutes ces choses influencent la façon dont je pense pouvoir faire une image qui attire immédiatement l'attention des gens. » (Paris Match 2009)

Le pouvoir évocateur de l'affiche tient sans doute à plusieurs de ses caractéristiques $^{5}$ : la palette de couleurs retient l'attention, donne un effet fané qui tranche avec les codes habituels de l'affiche électorale et accroche. Le code couleur de l'affiche utilise le bleu, le blanc et le rouge, choix attendu qui fait référence au drapeau américain. Pourtant, chaque couleur se démarque du tricolore habi-
-

5. Je remercie chaleureusement Jean-Louis Estève, professeur à l'école Estienne, et David Poullard, enseignant à l'école régionale des beaux-arts de Valence, qui m'ont apporté leurs compétences de typographes et de graphistes pour l'analyse de cette image. 
tuel. Le bleu pâle "tombé» avec du blanc ou le bleu marine presque noir sont fort différents du bleu Old Glory défini dans le système Standard Color Cards of America. Il en va de même pour le rouge de l'affiche, qui occupe la moitié du visage d'Obama. Certains ont voulu y voir une référence révolutionnaire alors que ce carmin usé n'est justement pas de gauche; c'est au contraire un vermillon adouci qui n'a rien du rouge communiste. La couleur jaune du papier casse les couleurs et leur enlève tout brillant. Nul besoin d'être un grand publicitaire pour comprendre que le choix d'un fond jaune, qui évoque un papier ancien et pauvre, joue ici un rôle important.

La manière dont le visage d'Obama est dessiné, le type de traits qui découpent les sourcils et les cheveux - traits anguleux comme faits au cutter, sans arrondis - suggèrent une image fabriquée à la va-vite, une impression pirate faite main, dans l'urgence. Les aplats de couleurs sans effets de matière amplifient un style graphique solidaire des techniques de la sérigraphie, du pochoir (D'Almeida 2003 : 11) ou du linogramme, typiques des pratiques militantes ${ }^{6}$. On pense par exemple à certaines affiches de Mai 68 (Fraenkel 2008 : 278) ou encore aux pochoirs du street art. Un détail vient cependant nuancer la référence au monde des activistes: des traits hachurés, un fini de qualité tranchant avec la simplicité sérigraphique ancrent l'affiche dans une tradition plus ancienne, celle de la gravure sur bois du xix siècle. Le visage d'Obama, découpé en deux parties, l'une bleu pâle, l'autre rouge carmin, est incliné, animé par de petites lumières dans les yeux. Tout un vocabulaire est ici réuni pour décrire un héros progressiste d'un autre temps, refusant la violence des codes électoraux, porteur d'une culture politique édulcorée, stylisée, allusive. Un héros à distance du monde qui délivre un message d'espoir curieusement orienté vers le passé, soutenu par une affiche résolument collector.

Nous ne pouvons pas cependant nous en tenir à une analyse de l'image qui lui attribuerait un pouvoir intrinsèque quasiment "magique». Nous devons également comprendre quelle conception de l'affiche en tant que document agissant, doté d'un pouvoir, d'un impact, est ici à l'œuvre. C'est donc à la genèse du document que nous allons nous intéresser. De quelle officine sort-elle? De quoi est faite l'agence Obey Giant?

\section{Une étrange agence de propagande}

$\mathrm{Au}$ début de l'histoire merveilleuse de l'affiche Hope, un constat fait par Fairey : il manque un portrait officiel d'Obama. Ce jugement sûr n'est pas celui d'un graphiste, mais bien d'un amateur de communication politique. Il révèle une autre facette de l'artiste, celle de propagandiste en chef de l'agence Obey Giant. L'agence fondée par Fairey est connue pour ses produits commerciaux (t-shirts, pochettes de disques, logos, affiches, etc.). Elle se présente comme un outil de production et une marque dont le logo étoilé apparaît sur tout ce qu'elle fabrique. L'affiche Hope prend donc place dans une lignée de créations graphiques dont elle est le produit phare. Il faut aussi prendre en compte le point de départ de la carrière de Fairey, qui a établi sa réputation comme afficheur plus que comme affichiste, comme diffuseur plus que comme créateur. L’agence Obey Giant a vocation à "propager » des images, et nous verrons que ce sont les stratégies de diffusion qui sont au cœur du succès de l'affiche. Enfin et surtout, l'agence cultive l'ambiguïté : elle se présente comme une officine au service d'un être imaginaire, André le Géant, 


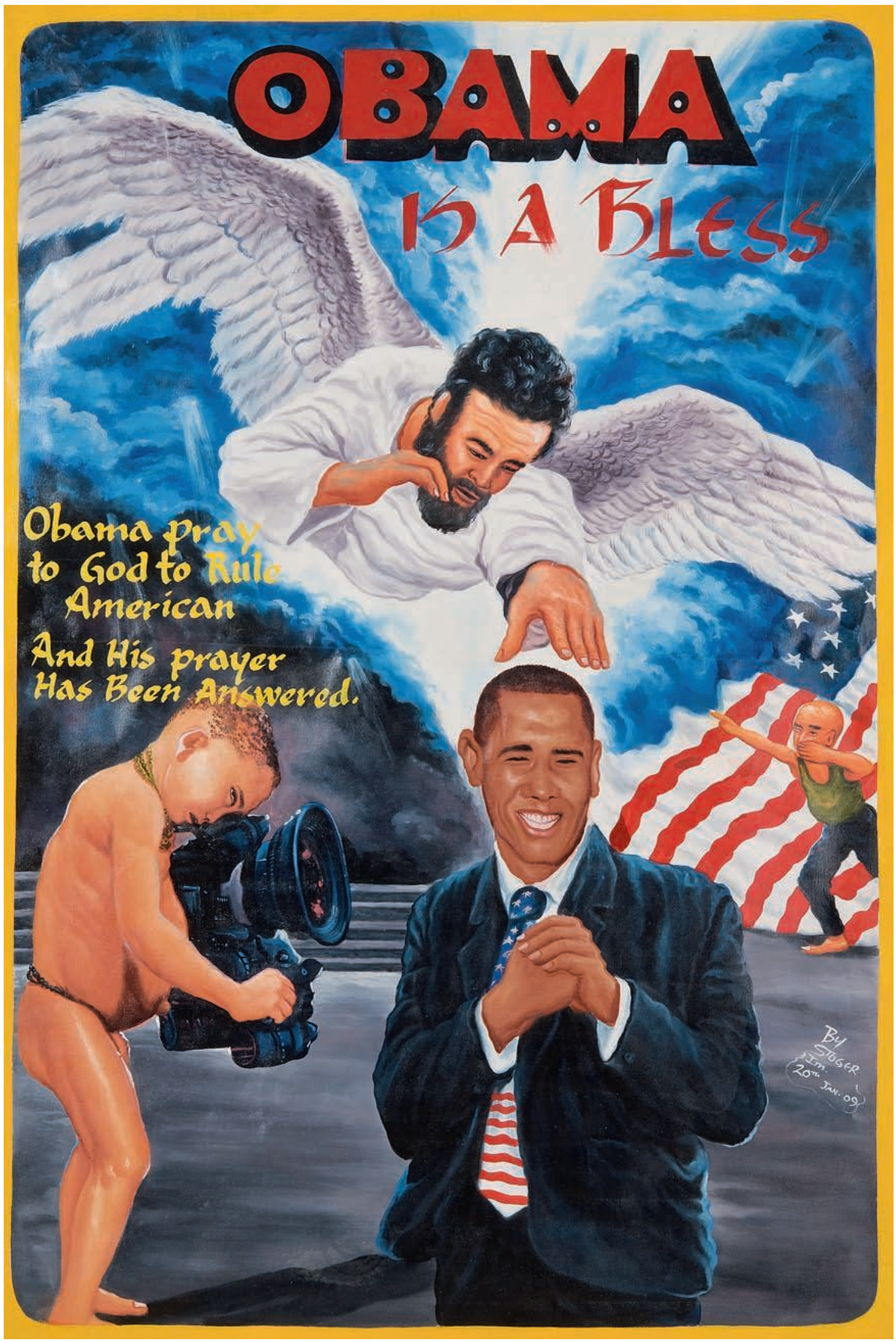

Fig. 4 Stoger, God is a Bless (2008), huile sur toile. Avec l'aimable autorisation de la Ernie Wolfe Gallery, Los Angeles. 
dont elle serait le service de propagande. Cet arrière-plan de contes et légendes, à la fois enfantin et infantile, ne l'empêche pas de développer une théorie de la communication politique - le nom même de la marque, "Obéis ", est déjà en soi tout un programme.

\section{L'ARTISTE ET SON GÉANT}

Une visite sur le site Internet de la marque Obey Giant ${ }^{7}$ s'impose. Créé en 1999, ce site efficace et plaisant conjugue une fonction documentaire - de nombreuses archives y sont présentées - et une fonction commerciale. Faisant office à la fois de boutique et de galerie, il permet d'une part de vendre les produits et d'annoncer les événements organisés par Fairey, d'autre part d'exposer et de proposer les œuvres à la vente. C'est en croisant les informations données sur obeygiant. com, les interviews de Fairey dans la presse, ses shows télévisés et la lecture de l'ouvrage Obey. Supply and Demand. The art of Shepard Fairey (2009), véritable bible destinée aux fans, que nous avons commencé notre enquête. Dès les premières pages du livre, on tombe sur la figure d'André le Géant, être graphique fabuleux créé par l'artiste en 1989, ancêtre aux origines de l'agence et dans la généalogie duquel s'inscrit Obama. La carrière artistique de Fairey commence en effet par une première campagne de propagande qui s'étend sur plusieurs années (1989-1994), et dont le thème principal est la promotion d'André par la diffusion du slogan : "André le Géant a une bande" (Andre the Giant has a posse) [fig. 5].

Expérience fondatrice, la création d'André le Géant procède d'un geste parodique, aux marges d'un travail de création. C'est en voulant apprendre à l'un de ses amis à faire des pochoirs que Fairey, alors gérant d'une boutique de skateboard, choisit par hasard, dans un magazine qui encombrait son comptoir, une publicité pour un catcheur : "Voilà ce que tu devrais prendre! Il est tellement laid, c'est génial!” J'ai décidé de faire glisser cet horrible visage de la catégorie ringard à la catégorie cool, un peu pour me moquer des autres skaters... Je venais de trouver ma voie! J'ai tout de suite réalisé un autocollant Andre the Giant has a posse $^{8}$." (Sugar Skateboard Magazine 2000) Le géant "ringard " n'est autre qu'André Roussimoff, célèbre catcheur affecté de gigantisme : il mesurait 2,24 mètres. En 1989, après avoir connu des années de gloire, sa santé se dégrade et il perd son titre de champion du monde des poids lourds. Lors de ses derniers combats, il peut à peine se déplacer. Il meurt en 1993 à Paris. Fairey décide de coller son sticker "ridicule » un peu partout, s'obstine et se consacre pendant des années à une campagne de propagande absurde. Puis, devant le succès du Géant, il passe en 1993 à la fabrication d'affiches en sérigraphie. "Ça a rapidement tourné à l'obsession, je collais de plus en plus d'affiches ", déclare-t-il (ibid.). Grâce à la diffusion massive des affiches et des stickers, il finit par s'attirer le respect de nombreux acteurs de la contre-culture. "Shepard took something that promote absolutely nothing and made it represent something simply by promoting it. Consciously or not, it's brilliant! » (Taylor in Fairey 2009)

Jusque-là, la carrière de Fairey et de son Géant demeure relativement confidentielle. André agrandit sa bande d'année en année : les adolescents l'aiment bien et se plaisent à l'afficher un peu partout. Fairey le décline sur plusieurs supports - t-shirts, stickers, affiches. Steven Heller, qui s'entretient avec Fairey en 1994 (AIGA website 2004), analyse l'ambiguité de la figure du Géant : à la fois Big Brother orwellien et empreinte d'un humour inhérent au visage de bon bougre d'André le Géant. Cette ambiguïté est l'un des mots clés de la doctrine 
de Fairey, qui a choisi de n'associer aucun message au Géant pour éviter tout réflexe d'adhésion et/ou de rejet. Mieux, en diffusant une image ambiguë, un message dénué de sens intentionnel, Fairey découvre le second dogme de son agence : ce sont les spectateurs qui créent André à leur guise, en fonction de leur personnalité. Si certains rejettent l'affiche, affirme-t-il, c'est parce qu'ils sont paranoïaques et conservateurs : l'affiche les menace. Ceux qui l'acceptent et l'aiment sont proches de la contre-culture, attirés par les pratiques rebelles et anti-conventionnelles. L'analyse semble naïve, mais elle illustre bien l'argumentaire de l'agence, qui manie sans cesse simplification et assignation.

OBEY GIANT, UNE AGENCE DE PROPAGANDE

En 1995, le destin de l'agence et du Géant prend un tour nouveau car Fairey éprouve un choc décisif en découvrant le film de science-fiction de John Carpenter, They live ${ }^{9}$ (1988). Ainsi le terme obey, directement emprunté au film, devient à la fois le maître mot de l'agence, désormais baptisée Obey Giant, et son logo. Écrit en lettres blanches sur fond rouge ${ }^{10}$, le mot apparaît sur les affiches sous l'image du Géant. Le message est une citation directe du film de Carpenter : le héros, Nada, découvre avec stupeur ce qu'est l'environnement urbain; grâce à des lunettes spéciales, il peut lire les messages subliminaux cachés sous les affiches et découvre les coulisses du régime manipulateur imposé à la société par des aliens.

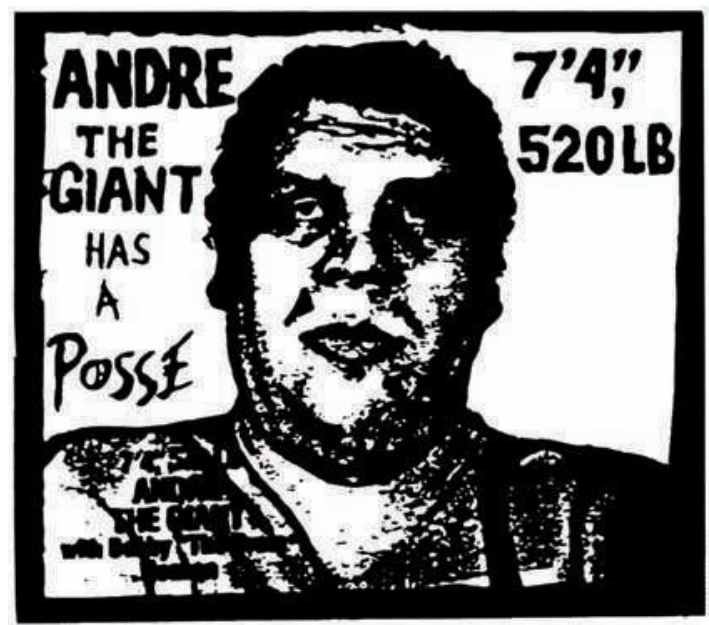

Fig. 5 Sticker de Shepard Fairey, 1989 @ Shepard Fairey/ Obey Giant Art, droits réservés.

L'agence intègre quelques références culturelles telles qu'Alexandre Rodchenko ou Barbara Kruger, dont on retrouve sans peine les citations graphiques dans les nouvelles affiches d'André. Sous ces diverses influences, le visage de Roussimoff évolue vers un masque plus stylisé, plus universel, une sorte de Big Brother proche de l'affiche du film 1984. Fairey, en s'emparant du Obey de Carpenter et en l'intégrant aux nouvelles affiches d'André le Géant, réalise un coup de maître : les gens commencent à afficher illégalement les posters d'André sur les murs de la ville (fig. 1). Le message Obey, «Obéis! », est donc contredit par le mode d'affichage lui-même. Obey, on l'aura compris, en vient à signifier disobey par une contradiction pragmatique entre l'ordre donné et le mode de présentation de cet ordre.
-

9. Curieusement traduit en français par Invasion Los Angeles, le film est largement inspiré de la nouvelle de Ray Faraday Nelson, Eight o'clock in the morning (1963).

10. Le logo Obey emprunte beaucoup à Barbara Kruger mais, contrairement à elle, Fairey n'a pas de message à inscrire sur ses affiches. 
La nouvelle affiche d'André le Géant complète la doctrine de l'agence. Elle ajoute aux deux principes fondateurs, l'ambiguïté et le refus de message, une nouvelle dimension, la contradiction pragmatique. La réception de l'affiche révèle à Fairey les mécanismes du système capitaliste et de la consommation, en particulier ceux de l'offre et de la demande. Ou'importe l'absurdité de l'affiche, qui combine l'image d'un catcheur, des symboles vaguement communistes - le rouge - et un message paradoxal - obey pour disobey - (Sugar Skateboard Magazine 2000). Fairey comprend que, ce qui compte, c'est l'aura de rébellion qu'elle véhicule et qui fait d'elle un produit à vendre. Plus les images du Géant sont diffusées, plus elles prennent de la valeur pour les professionnels de la communication car elles semblent tout droit sorties de la niche rebelle de l'art de rue. Au même moment, elles se dévaluent auprès de ceux qui arboraient Obey Giant comme la marque d'appartenance à un club élitiste (Fairey $2009:$ 1).

Désormais, la doctrine de l'agence est bien établie et Fairey se lance dans la création d'une emblématique qui n'a rien à envier au royaume de Syldavie ${ }^{11}$. Obey Giant est ainsi doté d'un second logo emprunté à la propagande bolchevique - une étoile rouge à cinq branches -, d'un grand sceau, d'un drapeau, de décorations et d'insignes divers, de billets de banque, de timbres et même de projets de bâtiments (fig. 7). Ces créations graphiques font apparaître un jeu ambivalent : elles peuvent se lire à la fois comme la dénonciation d'un ordre graphique autoritaire, voire dictatorial, et comme une exhibition fascinée de ses ressources ornementales. On ne peut qu'évoquer ici le roman de George Orwell, 1984, qui décrit l'emprise de l'emblématique d'Océania sur les enfants : "[...] ils adoraient le Parti et tout ce qui s'y rapportait : les chansons, les processions, les bannières, les randonnées en bandes, les exercices avec des fusils factices, l'aboiement des slogans, le culte de Big Brother. C'était pour eux comme un jeu magnifique. » (Orwell 2009 [1949] : 38) Ainsi, malgré leur caractère parodique, les créations de Fairey témoignent d'une jubilation qui pourrait apparaître comme une certaine forme de complaisance.

OBAMA LE GÉANT, UNE AFFICHE CRYPTÉE ?

L'appartenance de l'affiche Hope à la gamme des produits de l'agence Obey Giant soulève plusieurs questions, en particulier celle de son statut. Doit-on lui appliquer les critères de qualité défendus par la marque, à savoir qu'une bonne affiche est une affiche ambiguë, vide de message, proposant un programme d'action contradictoire ("obéis» et "désobéis») ? Doit-on considérer Obama comme un géant, à l'instar d'André? De telles hypothèses suggèrent que l'affiche, fêtée comme une contribution militante, serait en fait un piège : sous ses aspects de propagande pro-Obama, elle véhiculerait un contre-message lisible par les quelques happy few initiés aux œuvres précédentes de Fairey.

En ce cas, le message « Hope " accolé à l'image passéiste d'Obama pourrait être interprété comme son contraire. L'espoir serait une valeur à la fois affirmée et niée. Les nombreuses références de l'affiche aux traditions graphiques de luttes anciennes relevées plus haut porteraient en quelque sorte un message contradictoire : l'espoir appartient au passé et il conviendrait alors de l'interpréter comme une valeur moribonde, chargée d'ironie mais aussi de nostalgie. L'espoir politique

11. Hergé, Le Sceptre d'Ottokar $(1939 ; 1947$ pour la version en couleur]. ne serait plus qu'un élément participant d'un style ornemental, un mot d'ordre aussi daté que l'étoile rouge. 


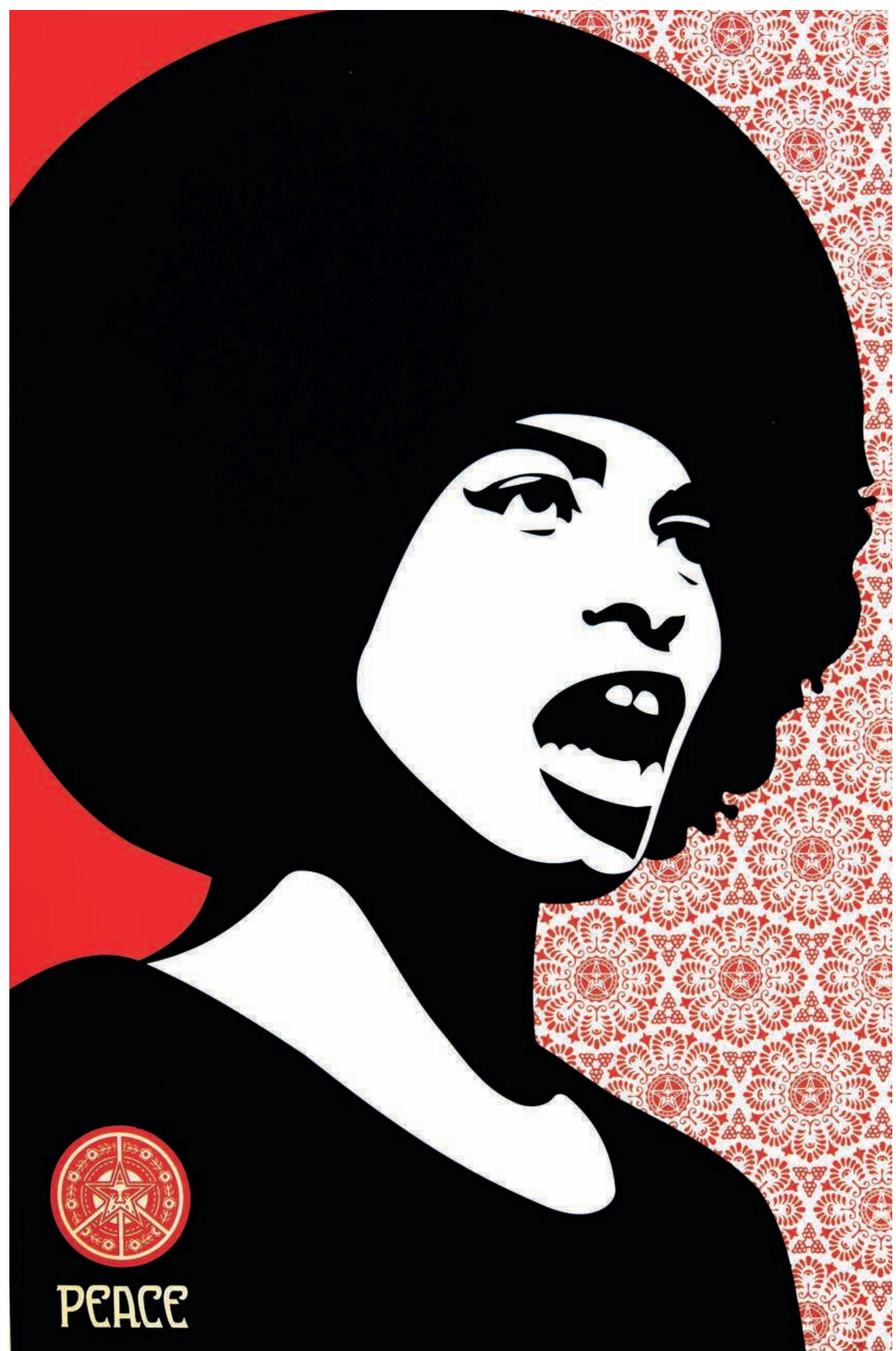

Fig. 6 Angela Davis, 2005 @ Shepard Fairey/Obey Giant Art, droits réservés. 

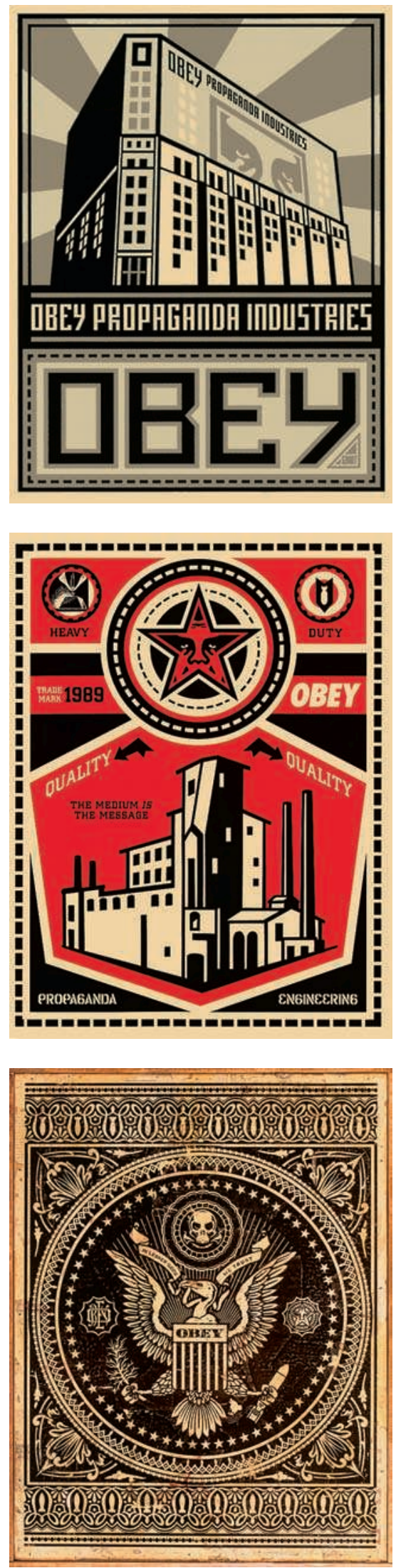

Un détour par les archives de l'agence Obey Giant pourrait nous conforter dans cette lecture de l'affiche. Mentionnons en particulier le très curieux panthéon des héros de l'agence: lorsqu'en 1992 cette dernière prend la forme d'un service de propagande parodique, en même temps qu'elle se dote d'une emblématique complète (sceaux, drapeaux, timbres, etc.), elle entreprend la production de portraits de leaders de tous poils. Aux côtés d'Angela Davis et de plusieurs héros des Black Panthers, de Mao, Lénine et autres, apparaissent des généraux prussiens ou des chanteurs punk rock. Surgit ainsi tout un théâtre de marionnettes dont le point commun semble être la stéréotypie. Toute icône "typique » est bonne à prendre, à emprunter et à retravailler jusqu'à devenir une nouvelle vignette de la collection de l'agence (fig. 6).

Replacer l'affiche dans son contexte de production nous a conduits à l'interpréter au sein du dispositif de propagande parodique construit par Fairey. Il va de soi que cette première conclusion doit être dépassée et confrontée à sa prise en charge par une seconde « agence » de nature différente, celle de la campagne électorale d'Obama.

\section{Une affiche de campagne}

C'est bien la campagne présidentielle qui a donné à l'affiche Hope sa dimension d'image culte et d'image virale. Pensée en dehors de ces circonstances, ramenée à ses qualités plastiques intrinsèques et à l'agence qui l'a produite, l'affiche resterait engoncée dans un système de propagande parodique dont on a vu les limites. Adaptée aux normes d'une réelle campagne politique et située dans un dispositif au centre duquel se trouve non pas le masque fantomatique d'André le Géant, mais un candidat à stature de géant, Barack Obama, elle se modifie radicalement. Il nous faut donc achever notre enquête par une incursion au cœur même de la machine de propagande électorale démocrate qui, tel un monstre marin, a absorbé le poster Hope puis rejeté une image quasiment miraculeuse. L'affiche, ainsi métabolisée, s'est révélée exceptionnelle, de cette classe d'affiches après laquelle courent nombre de graphistes, et Fairey en particulier : elle s'impose comme «image virale "; la machine électorale a fait éclore son précieux potentiel. Plusieurs éléments doivent être examinés pour étayer et préciser cette analyse. Il faut rappeler ce qu'a été cette campagne, jugée exceptionnelle dans l'histoire de la propagande électorale; comprendre comment les stratégies de communication des démocrates et un produit signé Obey Giant se sont appariés; enfin, expliciter ce que l'on entend par «image virale », statut grâce auquel l'affiche Hope a finalement acquis sa dignité.

Rappelons tout d'abord que, pour accéder au rang d'image de campagne officiellement acceptée par le parti démocrate, l'affiche a dû se conformer à quelques normes : adopter le Gotham, typographie officielle de la campagne, ainsi que l'un des slogans officiels, «Hope ». Fairey a également dû faire disparaître de son œuvre le logo étoilé de l'agence Obey Giant, détail qui a son importance : l'affiche n'était en effet acceptable qu'une fois débarrassée de sa marque de fabrique. L'image d'Obama s'est alors détachée du panthéon des leaders de l'agence, s'affranchissant d'un cadre interprétatif pour le moins problématique. «The original screenprint has my little 
Obey logo on his button but the one for the street is not Obey branded.» (Fairey 2009 : 272) Nous sommes en janvier 2008, l'affiche ainsi neutralisée va pouvoir intégrer un nouveau réseau de diffusion, celui des militants pro-Obama.

C'est dans ce nouveau contexte que plusieurs des caractéristiques de l'affiche se transforment. Revenons par exemple sur l'ambiguïté du message «Hope». Nous avons vu que, dans le système parodique et ironique d'Obey Giant, inauguré par le slogan fondateur de l'agence, "Obey", un message affirme à la fois son contenu et son contraire ${ }^{12}$. Si cette ambiguïté garde toute sa pertinence pour les professionnels de la campagne d'Obama, elle est cependant pensée d'une tout autre façon. Ces derniers l'envisagent en effet comme un atout dans la mesure où chacun peut donner un sens personnel au message qui lui est adressé, mais la polysémie du terme employé n'est censée véhiculer aucune contradiction. Ashley Etienne, porte-parole de la campagne d'Obama en Virginie, exprime clairement cette conception de l'ambiguité au sujet d'un autre mot d'ordre de la campagne, "Change " : "The extraordinary strength of the message is that "change" is ambiguous. You can't define it precisely, it bears several meanings. Its meaning is so broad that it can encompass every thing, every subject. It is sufficiently large to let people project in it. It was tailored so that each individual can invest in it. Change does not mean the same thing to different people. " (Moderniser la vie politique... 2009: 24)

On se souvient que Fairey avait lui-même remarqué la possible diversité des lectures du slogan «Obey " qu'il placardait sur tous les supports urbains. C'était, pour le graphiste, l'occasion de distinguer les bons lecteurs des mauvais : selon le principe naïf du "c'est celui qui le dit qui l'est», ceux qui n'aimaient pas l'affiche Obey étaient, selon lui, des paranoïaques! L'ambiguité de "Hope», comme celle de "Change", est tout autre, entendue comme un critère susceptible de rassembler des publics et non de les classer en groupes antagonistes. On retrouve ici l'un des grands principes de la campagne enseignés aux militants : "Include». Il ne s'agit pas simplement de convaincre, mais d'inclure le plus possible d'électeurs dans l'action de propagande.

D'autres renversements vont se produire, qui touchent aux enjeux même de la diffusion de l'affiche. Fairey cherchait, par l'affichage illégal d'Obey, à réveiller les passants, à leur faire la leçon par une contre-leçon. Une logique de distinction entre initiés appartenant à l'univers des cultures alternatives (skaters, rockers, graffiteurs, etc.) et citadins passifs sous-tendait le projet. Le coup de force de la campagne électorale d'Obama, et son coup de génie, a été au contraire de miser sur l'empowerment de tous les militants. Chacun, en militant pour Obama, était invité à agir à sa façon, à s'approprier personnellement la cause, à comprendre que sa victoire serait en fait la sienne - "votre victoire", comme l'affirma avec force Obama en intitulant son ultime discours du 4 novembre 2008: This is your victory. L'affiche Hope est l'une des innombrables créations, innovations et trouvailles qui n'ont cessé d'enrichir la campagne. Elle a favorisé l'engagement d'individus issus de diverses contre-cultures, qui sont ainsi entrés dans le mainstream du militantisme.

Du point de vue des concepteurs de la stratégie de communication d'Obama, l'affiche Hope répondait de façon évidente à un double objectif : enrôler les jeunes pour qu'ils votent, faire valoir l'anti-establishment dont ils se réclament et faire circuler un parfum de contestation artistique dont tout publicitaire connaît l'efficacité13. Il n'en reste pas moins que l'officialisation de l'affiche, saluée comme une attraction inattendue qui venait égayer le déroulement d'un spectacle bien rodé, a surpris.
CI-CONTRE

Fig. 7,8 et 9

Projets architecturaux et sceau (c) Shepard Fairey/Obey Giant Art, droits réservés.

\section{-}

12. C'est à Orwell, dans son roman 1984 , que revient l'idée de caractériser les régimes totalitaires par l'usage de slogans contradictoires. On peut ainsi lire sur les murs de la ville d'Océania les trois slogans du Parti : «La Guerre c'est la Paix », «La Liberté c'est l'Esclavage », « L'lgnorance c'est la Force » (Orwell 2009 [1949]: 41].

13. Voir à ce sujet la démonstration toujours d'actualité de Naomi Klein, «Tout est alternatif : le marché jeunesse et le marketing du cool », dans No logo (2001 : 93-120). 
-

14 Dans toute cette partie, nous avons largement utilisé l'excellent rapport sur la campagne de la fondation Terra Nova (Moderniser la vie politique... 2009).

15. «Organisateurs sur le terrain »; nous gardons l'expression américaine qui fait écho à community organizers.

16. En 2008, le chanteur Will.i.am compose la chanson Yes we can et produit une vidéo de soutien à Obama qui connaît un très grand succès.

\section{RÉVOLUTION MILITANTE ET AFFICHE}

À Chicago, le 4 novembre 2008, lorsqu'il prononce son discours de victoire - le This is your victory cité plus haut-, Obama évoque en des termes particulièrement élogieux la campagne elle-même : «Et au chef de campagne, David Plouffe, le héros méconnu de celle-ci, qui a mis sur pied la meilleure campagne politique, je pense, de l'histoire des États-Unis; à mon grand stratège, David Axelrod, qui a été mon partenaire tout au long de la campagne ; à la meilleure équipe jamais formée dans l'histoire de la politique et qui est la raison première de cette histoire : je vous suis à jamais reconnaissant pour tous vos sacrifices. » (Obama 2009 : 108109) Trois questions nous intéressent ici : en quoi les caractéristiques exceptionnelles de cette campagne ont-elles influé sur le destin de l'affiche Hope? Dans quelle mesure celle-ci a-t-elle été «interprétée ", au sens que C. S. Peirce donne à cette notion, par la campagne? Enfin, comment l'affiche a-t-elle été réinventée en tant qu'image virale?

L'exceptionnalité de la campagne ${ }^{14}$ réside tout d'abord dans le nombre de ses militants : ils étaient 1,2 million à ratisser le territoire et à contacter directement les électeurs. Ce réseau d'une extraordinaire densité était fortement encadré par un staff de campagne qui comptait sur 2700 field organizers ${ }^{15}$ salariés, épaulés par 5000 bénévoles qui n'ont cessé de quadriller le pays. On considère qu'au total 10 millions d'Américains se seraient mobilisés. La campagne d'Obama restera comme la plus grande campagne électorale du siècle.

Mais le nombre ne suffit pas à expliquer en quoi cette campagne a été une véritable "révolution militante», comme l'affirment les professionnels de la communication politique. En réalité, durant ces mois de travail acharné, c'est une nouvelle conception du militant lui-même qui a été mise en œuvre. En rupture avec des stratégies à la Kennedy, fondées avant tout sur la communication de masse, ou avec la communication segmentée à la Bill Clinton, qui s'appuyait sur les leaders communautaires, les stratèges du futur président ont choisi d'appliquer les principes du micro targeting : un marketing visant des cibles minuscules et prônant le peer to peer, c'est-à-dire une diffusion des messages entre pairs, de proche en proche. Les sympathisants, organisés en groupes géographiques et thématiques, disposaient de moyens d'action adaptés : des kits de formation, un package de documentation de campagne, un programme de porte-à-porte (neighbour to neighbour).

Toute l'organisation de la campagne reposait en outre sur la valorisation du travail des volontaires. Des récompenses étaient octroyées aux meilleurs; les idées et points de vue des militants les plus créatifs remontaient jusqu'aux directeurs de campagne et jusqu'à Obama lui-même. L'histoire du fameux Yes we can, inventé par des militants lors d'une réunion et repris au plus haut niveau, en témoigne. La capacité de la campagne à se réapproprier les meilleures initiatives de ses supporters, comme celles de Fairey et du chanteur Will.i.am ${ }^{16}$, concrétise l'idée que le pouvoir appartient aux militants et que ces derniers influencent véritablement la campagne.

C'est ainsi que s'incarne le principe d'empowerment et, avec lui, l'engagement résolu de millions d'individus. Un analyste souligne l'importance de la projection de soi dans l'action militante : «Le programme publicitaire de trente minutes que diffuse Obama le 29 octobre est structuré autour d'une série d'histoires personnelles. Sur le terrain, les volontaires sont par ailleurs encouragés à s'approprier les messages de la campagne et à les narrativiser à l'aune de leur expérience personnelle. Il est d'ailleurs fascinant de constater que les militants, 
lorsqu'on les interroge sur la campagne, ne parlent pas du tout de politique, peu d'Obama, beaucoup du changement et essentiellement d'eux-mêmes... " (Moderniser la vie politique... 2009 : 25) L'intérêt personnel, parfaitement encadré et canalisé par une communication interne constante et efficace contrôlée par le directeur de campagne, David Plouffe, trouve donc toute sa place dans l'action collective.

Le succès de la campagne résulte aussi de choix portant sur le message délivré et sur les moyens de sa diffusion. La grande cause du changement, noyau sémantique de tous les discours, a été déclinée sur le modèle des campagnes caritatives du type Téléthon. Il ne s'agit pas de voter pour Obama mais pour la cause. Un intense travail de recrutement via Internet, en particulier sur Facebook, My Space et les réseaux communautaires, accompagne ces choix stratégiques. Le modèle caritatif s'est révélé d'une grande efficacité pour la trésorerie de la campagne. L'importance des dons en ligne, parfois modestes mais innombrables, autorise à parler d'un véritable financement populaire.

Évoquons pour terminer une innovation largement saluée par les analystes: pour la première fois, la fusion entre l'action sur Internet et l'action sur le terrain a été privilégiée et parfaitement maîtrisée. Les activités des militants, recrutés et organisés grâce à Internet, ont été encadrées et coordonnées sur le terrain dans le moindre détail. L'articulation on line-off line est sans doute l'une des principales leçons techniques de l'élection.

Maintenant que nous avons campé la physionomie exceptionnelle de la campagne, nous sommes mieux armés pour discerner comment l'affiche Hope s'accorde avec les choix des propagandistes démocrates. L'expérience acquise au service d'André le Géant semble en effet sur bien des points faire écho, à un niveau microscopique, à celle qu'ont menée, à grande échelle, les stratèges de la campagne. D'un point de vue quantitatif tout d'abord, l'affiche pro-Obama de Fairey, comme tous les posters de l'agence, vise à une diffusion maximale. Par le passé, c'est Fairey lui-même qui s'est entièrement consacré à la diffusion de ses affiches dans les villes, passant la majeure partie de son temps à placarder ses œuvres sur les murs, les panneaux publicitaires, le mobilier urbain et autoroutier, et sur tous les supports possibles ${ }^{17}$. Comme on l'a vu, la force initiale de Fairey est celle d'un diffuseur plus que d'un créateur. Mais, parallèlement à cet intense travail de terrain, Fairey gère le site d'Obey Giant grâce auquel il vend et diffuse ses créations auprès d'un public d'amateurs et d'artistes de rue qui, à leur tour, placardent les produits de l'agence. En entrant dans l'immense réseau de la campagne électorale, l'affiche Hope a donc enfin trouvé LE réseau exceptionnel auquel son créateur n'a cessé de rêver.

Soulignons également l'importance du peer to peer, le soutien apporté par de petits groupes capables de s'engager et de s'atteler durement à la tâche, qui caractérise à la fois le dispositif de distribution d'Obey Giant et celui de la campagne d'Obama; sans oublier le principe d'empowerment, l'accueil valorisant les supporters, qui mise à la fois sur leur propre capacité d'action et sur leur sentiment d'acquérir du pouvoir par procuration : faire partie du posse d'André le Géant c'est "être cool ", appartenir au monde des rebelles; soutenir Obama, c'est contribuer personnellement au destin de l'Amérique. Dans les deux cas, le fait même d'acquérir l'image et de l'afficher a des effets sur la personne. Enfin, la machine démocrate et la petite entreprise de Fairey partagent le même souci de l'articulation entre l'on line et l'off line, entre l'action en ligne et l'action sur le terrain. Pour l'une comme pour l'autre, l'espace public est tout autant l'esde 2,5 millions de stickers, 45000 affiches et 1000 pochoirs autoproduits ! (Fairey 2009 : 288) 
pace virtuel d'Internet et de ses réseaux que l'espace physique avec ses rues, ses quartiers, ses villes.

Ces diverses affinités nous montrent que l'intégration de l'affiche dans la campagne n'a pas constitué la rupture tant commentée; il serait beaucoup plus juste de comprendre cette intégration comme un processus d'interprétation. C'est parce qu'elle a été «traduite " en affiche de campagne que l'image, exposée au regard de millions de spectateurs, valorisée comme contribution méritante d'un fils de l'anti-establishment et conforme en cela à la révolution militante en cours, a connu son assomption.

\section{FANTÔMES, VIRUS ET GÉANTS}

Il nous reste maintenant à apporter à notre dossier une dernière pièce susceptible d'éclairer autrement le parcours accompli. Nous avons pris acte de l'admiration qu'a suscitée la campagne électorale chez les professionnels. Quelques analystes ont reconnu dans les choix opérés par les stratèges d'Obama la présence implicite, camouflée, des théories d'un homme, Saul Alinsky, fondateur du community organizing (Behrent 2008). Militant radical et réformiste, impliqué dans plusieurs luttes des années 1950 et 1960 dans les quartiers noirs du sud de Chicago, Alinsky a mis au point des principes d'organisation des communautés qui constituent le socle invisible de la campagne du sénateur de l'Illinois. Ainsi, plusieurs des principes fondamentaux que nous avons mentionnés plus haut sont directement issus des stratégies de contestation d'Alinsky. Par exemple, la notion de field organizers - ces militants pro-Obama chargés de l'organisation des petits groupes de volontaires qu'ils recrutaient autour d'eux - est au centre des pratiques de l'animation sociale d'Alinsky. En formant à ses méthodes de très nombreux organizers, disciples qui à leur tour ont encadré et formé des animateurs, Alinsky a changé le visage de la contestation politique aux ÉtatsUnis. Par ailleurs, l'idée, essentielle au succès de la campagne, que l'organizer doit partir des intérêts personnels des individus pour les enrôler est aussi un principe fondateur de la méthode d'Alinsky : celui-ci ne croyait pas en la force des théories politiques et lui opposait systématiquement la nécessité de l'action sur le terrain. Enfin et surtout, il a constamment fait l'éloge du pouvoir, fustigeant ceux qui, par moralisme, n'y voyaient qu'une idée dévoyée de la lutte. Pour Alinsky, l'organizer est celui qui, intégré à la communauté dans laquelle il agit, fait comprendre aux opprimés qu'ils peuvent acquérir du pouvoir et ainsi obtenir des résultats concrets. On retrouve ici la notion d'empowerment, issue de la psychologie communautaire ${ }^{18}$, qui s'est développée dans le monde du travail social. Il est tout à fait saisissant de voir ressurgir, au cœur de la campagne électorale et en tant que techniques de mobilisation, plusieurs des concepts et des méthodes de la contestation sociale des années 1950 et 1960, désormais utilisés par le marketing électoral.

L'effet de surprise que constitue cette découverte est redoublé lorsque l'on sait qu'Hillary Clinton a consacré sa thèse ${ }^{19}$ à Alinsky, et surtout que l'un des organi-

18. Cf. Rapapport 1984 et 1987 ; Lebossé et Lavallée 1993; Gibson 1991.

19. Soutenue en 1969 , la thèse s'intitule : There is only the fight: An analysis of the Alinsky model. zers de Chicago, formé en 1985-1988 aux méthodes d'Alinsky par un disciple de ce dernier, n'est autre qu'Obama lui-même. Très discret sur cette filiation indirecte, Obama y fait plusieurs fois allusion dans son autobiographie, Dreams for my father (2008 [1995]). Le récit de ses années d'organizer dans le sud de Chicago décrit concrètement les principes qu'il appréciait et s'efforçait de suivre : "L'action, le pouvoir, l'intérêt particulier. J'aimais ces concepts », écrit Obama. On ne saurait 


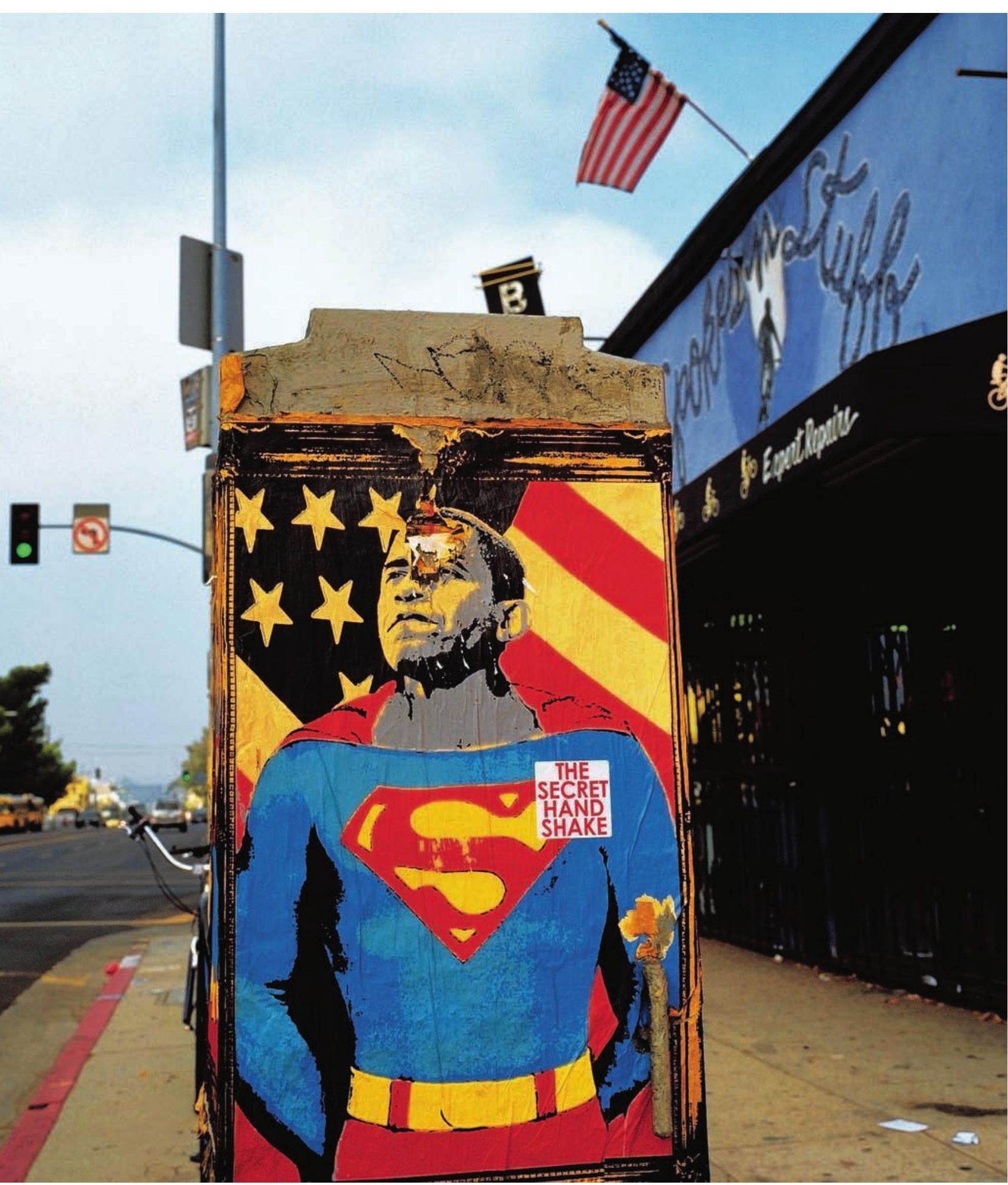

Fig. 10 Melrose Avenue. Los Angeles, Californie, octobre 2008 @ Alessandra Sanguinetti/Magnum Photos. 
- 0

20. Obama 2008 [1995] : 155, cité et traduit par Behrent 2008.

21. Cf. Wilson F. Ralph (2000), «The six principles of viral marketing », Web Marketing Today

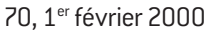

22. « Je sais faire des images virales et des images à caractère universel », déclare Fairey à ParisMatch (2009).

23. Nous soulignons. mieux résumer la théorie d'Alinsky ${ }^{20}$. La découverte de cette strate cachée de la campagne ouvre un nouvel espace de réflexion, qui nous invite à donner un tour plus spéculatif à l'analyse de notre objet, l'affiche Hope.

Tout comme l'affiche Hope est hantée par des références au monde de la propagande révolutionnaire, à l'image culte de Che Guevara notamment, tout comme l'affiche mime, nous l'avons vu, le style des sérigraphies militantes, on peut considérer que l'exceptionnelle campagne de Plouffe est elle aussi hantée par un passé contestataire habilement détourné. Au final, on peut se demander si une même nostalgie et une même ironie n'irriguent pas et l'affiche et le plan de campagne. On peut s'interroger sur la nature spectrale des deux agences qui ont fait l'affiche : au fantôme étrange du catcheur André le Géant autour duquel Obey Giant s'est développé semble correspondre celui d'Alinsky, maître secret et pour ainsi dire dévoyé du combat non plus politique mais politicien des démocrates.

Avant de refermer le dossier, il nous reste à revenir sur une notion que nous avons souvent évoquée, celle d'«image virale ». L'expression est issue du marketing, et plus précisément des techniques de lancement de produits ${ }^{21}$. On sait que l'affiche Hope est reconnue comme telle et que pour son créateur cette qualité est une consécration ${ }^{22}$. Ou'est-ce qu'une image virale? C'est une image qui se transmet comme un virus, de proche en proche, et qui affecte celui qui la reçoit. Si les diffuseurs d'une image virale ne sont pas malades, ils sont cependant affectés par l'image qu'ils prennent plaisir à transmettre. Du point de vue du marketing, il s'agit d'une technique de promotion économique et efficace, fondée sur le principe du bouche à oreille et reposant sur la participation active du consommateur, lui même propagateur de la réclame. Dans le cas de l'affiche Hope, c'est le programme d'action inscrit dans l'affiche qui s'est imposé à tous, porté par une stratégie d'empowerment qui n'est autre qu'une manière de donner le pouvoir aux afficheurs. L'affiche a enflammé la campagne, faisant monter la fièvre militante alimentée par le plaisir de diffuser une image forgée dans les laboratoires du street art et qui plaît autant aux diffuseurs qu'aux collectionneurs. La campagne ressemble alors à un jeu; elle s'accorde parfaitement au principe n 6 d'Alinsky: «Une tactique n'est bonne que s'il y a du plaisir à l'appliquer. " (1976 [1971] : 111)

En tant qu'image virale, l'affiche Hope participe avec efficacité à un ultime et cruel détournement de la théorie du militant des ghettos noirs de Chicago. «L'ego de l'organizer, écrit Alinsky, doit être envahissant au point que sa propre personnalité et son assurance doivent devenir contagieuses ${ }^{23}$ et créer un ego de masse qui permettra de transformer le désespoir des gens en une volonté de vaincre.» (1976 [1971] : 120) Cette contagion n'était pour Alinsky qu'une étape nécessaire vers l'auto-organisation des communautés, jusqu'à ce qu'elles puissent se passer des organizers. Appliqué au lancement du candidat Obama, le principe de la contagion semble avoir été compris comme une fin en soi. Une fois le président élu et la révolution militante devenue un cas d'école du marketing politique, il n'est pas improbable que l'affiche Hope finisse par connaître le pire des sorts qui, selon Fairey, menacerait toute affiche : devenir du papier peint. 


\section{Bibliographie}

\section{Alinsky, Saul}

1976 [1971] Manuel de l'animateur social, trad. Odile Hellier et Jean Gouriou. Paris, Seuil.

\section{BARKHATOVA, Elena}

1992 Affiches constructivistes russes.

Paris, Flammarion.

\section{Behrent, Michael C.}

2008 «Saul Alinsky, la campagne présidentielle et l'histoire de la gauche américaine », laviedesidees.fr, 10 juin.

\section{Bonnell, Victoria E.}

1997 Iconography of power. Soviet Political Posters under Lenin and Stalin, Berkeley, University of California Press.

\section{Coouin, François-Xavier}

1989 « L'image de Lénine dans l'iconographie révolutionnaire et postrévolutionaire », Annales ESC (44)2 : 223-249.

\section{D’AlmeIda, Fabrice}

2003 «L'américanisation de la propagande en Europe de l'Ouest (1945-2003) », Vingtième Siècle. Revue d'histoire 80 : 5-11.

\section{FAIREY, Frank Shepard}

2009 Obey, Supply and Demand. The art of Shepard Fairey. Berkeley, Gingko Press.

\section{DANS FAIREY 2009}

Carlo McCormick, « Shepard Fairey:

Circulations 》.

Henry Rollins, « Shepard Fairey: the good propagandist ».

Ken Taylor, «Welcome to the Jungle Ramp ».

\section{FraenKel, Béatrice}

2008 « Les affiches de Mai 68, l'atelier populaire des Beaux-Arts », in Philippe Artières et Michelle Zancarini-Fournel (éd.), 68, une histoire collective (1962-1981). Paris, La Découverte.
GiBson, C.H.

1991 «A concept analysis of empowerment », Journal of advanced nursing 19 : 354-361.

\section{KLeIN, Naomi}

2001 No logo. La tyrannie des marques, trad. Michel Saint-Germain. Arles, Leméac-Actes Sud.

Lebossé, Yann et Lavaluée, Marguerite 1993 «Empowerment et psychologie communautaire. Aperçu historique et perspectives d'avenir », Les Cahiers internationaux de psychologie sociale 18 : 7-20.

MODERNISER LA VIE POLITIOUE : INNOVATIONS AMÉRICAINES, LEÇONS POUR LA FRANCE 2009 Olivier Ferrand (dir.), rapport de la mission d'étude de Terra Nova sur les techniques de campagne américaines.

OBAма, Barack

2008 [1995] Les Rêves de mon père. Paris, Presses de la Cité.

2009 La Promesse de l'Amérique. Paris, Buchet-Chastel.

OrWELL, George

2009 [1949] 1984. Paris, Gallimard [«Folio »].

RAPPAPORT, Julian

1984 «Studies in empowerment: introduction to the issues », Prevention in Human Services $3: 1-17$.

1987 « Terms of empowerment/exemplars of prevention: toward a theory for community psychology 》, American Journal of community psychology 15 : 121-148.

RodchenkHo, Alexandre Mihailovic 1988 [1928] «Contre le portrait composé, pour le cliché instantané », in Écrits complets sur l'art, l'architecture et la révolution, trad. Bernadette du Crest. Paris, Philippe Sers éditeur : 133-13?
SonTAG, Susan

1999 [1970] « Posters: advertisement, art, political artifact, commodity », in Michael Bierut, Jessica Helfand, Steven Heller et Rick Poynor (éd.), Looking Closer 3. New York, Allworth Press : 196-218.

2000 [1977] Sur la photographie, trad. Philippe Blanchard. Paris, Christian Bourgois éditeur.

\section{Articles de presse}

2000 «Shepard Fairey : afficheur », Sugar Skateboard magasine, août. 2004 Steven Heller, «Propaganda », AIGA website.

2008 «La révolution Obama son parcours, ses idées ses réseaux », Courrier international hors série, juin-juillet (portrait d'Obama par Fairey en couverture). 2008 Los Angeles Times, 30 mars. 2008 Washington Post, 18 mai. 2009 Régis Le Sommier, « Shepard Fairey raconte les secrets d'un portrait », Paris Match, 19 janvier. 2009 «Commemorative Cover february », Esquire, 20 janvier (portrait d'Obama par Fairey en couverture). 2009 Noam Cohen, «Le photojournalisme, une forme d'art? », New York Times, 9 avril, trad. in Courrier international 962, 6 novembre. 2009 Jean-Pierre Frimbois, « Obamart », Art actuel 62, mai-juin (portrait de Fairey en couverture) : 16-21. 2009 The Huffington Post, 12 juin.

\section{Film}

1988 They live [Invasion Los Angeles], John Carpenter.

\section{Site}

www.obeygiant.com 


\section{Résumé / Abstract}

Béatrice Fraenkel, L'affiche Hope. Portrait d'Obama comme Géant et comme virus - L'affiche Hope fait partie des événements de la campagne de Barack Obama. Inspirée de l'affiche représentant Che Guevara, elle a introduit une touche de contre-culture et séduit un large public. Elle est l'œuvre d'un street artist, Shepard Fairey, qui se réclame d'une approche parodique de la propagande politique. D'où les questions que l'on est en droit de se poser: l'affiche serait-elle une sorte de piège à double sens, véhiculant sur Obama un message ambigu ? À regarder de plus près l'organisation de la campagne électorale, qui fut la rampe de lancement de l'affiche, on découvre que la « révolution militante » prônée par les responsables du marketing d'Obama pourrait fort bien s'accommoder d'un détournement de références révolutionnaires. Ne retrouve-t-on pas, derrière la mobilisation massive de millions d'Américains, les principes détournés de l'organisation des quartiers pauvres de Chicago dans les années 1960 ? L'affiche Hope, teintée de nostalgie et d'ironie, ne serait alors qu'une image presque naïve au service d'une machine de propagande politicienne qui recycle sans état d'âme les expériences de lutte des plus opprimés.
Béatrice Fraenkel, The Hope poster. Obama as giant and as virus - The Hope poster was one of the key events of Barack Obama's presidential campaign. Inspired by a Che Guevara poster, it added a touch of counter-culture and helped to win over large numbers of people. The poster was the work of a street artist, Shepard Fairey, who describes his approach as a parody of official propaganda. This raises a number of legitimate questions: might the poster not be a sort of double-edged sword, giving off mixed and ambiguous messages about Obama? If we examine the organisation of his election campaign, responsible for launching the poster, we see that the "militant revolution" dreamt up by Obama's marketing people would have had no problem with traducing revolutionary images and ideas. In their mobilisation of millions of Americans, do we not see a traduced version of the organisation of poor Chicago districts in the 1960s? Considered from this perspective, the Hope poster, with its layers of nostalgia and irony, is little more than an almost naïve image deployed by a political propaganda machine unashamedly making use of experiences of militant struggle amongst the very poorest sections of society. 


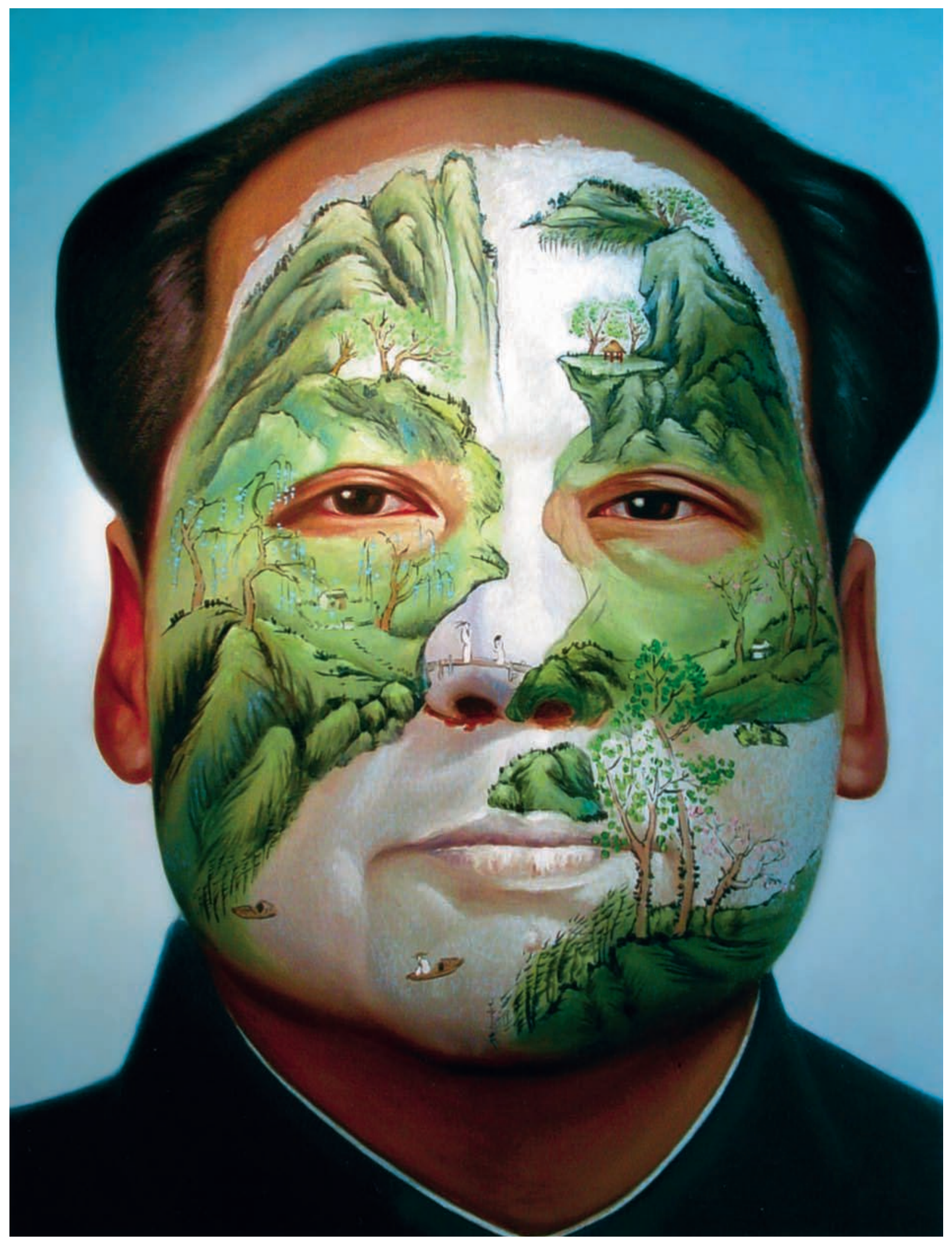

Fig. 11 Mao, Paysage de printemps, 2008, Huang Yan, huile sur toile, 150 × $120 \mathrm{~cm}$. Avec l'aimable autorisation de YU Gallery, Paris. 